\title{
IMPLEMENTASI TEKNOLOGI TEPAT GUNA SMART VILLAGE BERBASIS RASPBERRY PI PADA DESA PETANG
}

\author{
Candra Ahmadi ${ }^{1}$, I Gede Putu Wirarama Wedashwara ${ }^{2}$, \\ Dadang Hermawan $^{3}$, Joko Santoso ${ }^{4}$ \\ 1,4 Jurusan Sistem Informasi, Institut Teknologi dan Bisnis STIKOM Bali \\ 2Jurusan Teknik Informatika, Universitas Negeri Mataram \\ ${ }^{3} J u r u s a n$ Bisnis Digital, Institut Teknologi dan Bisnis STIKOM Bali \\ e-mail: candra@stikom-bali.ac.id ${ }^{1}$, wirarama@unram.ac.id ${ }^{2}$, \\ dadang@stikom-bali.ac.id ${ }^{3}$, joko_santoso@stikom-bali.ac.id ${ }^{4}$
}

\begin{abstract}
Abstrak
Desa Petang terletak di Kecamatan Petang, Kabupaten Badung. Desa ini berada di ketinggian 800 meter dari atas permukaan laut. Desa Petang merupakan salah satu desa yang dijadikan tujuan wisata di Bali. Desa petang merupakan desa agronomi/pertanian dan pariwisata. Desa petang memiliki potensi pertanian yang luar biasa terutama manggis, yang apabila dikelola dengan baik, maka akan menjadi Agro Wisata bagi desa petang. Selain pertanian, petang juga memiliki kekayaan alam yang luar biasa yang berupa pemandangan pegunungan dan sungai yang biasa dipergunakan sebagai arung jeram, namun sayang kondisi arung jeram di desa Petang seaakan matri suri karena tidak meiliki tata kelola yang baik dan sarana untuk promosi. Petang juga memiliki sentra sentra pengrajin perak yang berada pada desa tersebut. Permasalahan utam dalam industry perak adalah masalah produksi (stok bahan baku), Manajemen keuangan dan masalah pemasaran. Pada kegiatan ini akan dilakukan pendampingan dan pelatihan. Selain pelatihan dan pendampingan, pada kegiatan ini akan direncanakan membuat sistem informasi untuk desa berbasis raspberry pi, melakukan pelatihan entrepreneurship bagi aparat desa dan masyarakat desa petang untuk menumbuhkan sentra sentra industry kecil, Untuk mitra UKM yang terlibat selain dilakukan pelatihan akan dibangun sistem e-commerce agar meningkatkan pendapatan UKM.
\end{abstract}

Kata kunci: Sistem Informasi, Smart Village, Raspberry-pi

\begin{abstract}
Petang Village is located in Petang District, Badung Regency. This village is located at an altitude of 800 meters above sea level. Petang Village is one of the villages that is used as a tourist destination in Bali. The evening village is an agronomy / agriculture and tourism village. The evening village has tremendous agricultural potential, especially mangosteen, which, if managed properly, will become an agro tourism for the evening village. Apart from agriculture, evenings also have extraordinary natural wealth in the form of views of mountains and rivers which are commonly used for rafting, but unfortunately the condition of rafting in Petang village is seaakan matri suri because it does not have good governance and means for promotion. Evening also has a center for silver craftsmen located in the village. The main problems in the silver industry are production problems (raw material stocks), financial management and marketing problems. In this activity, assistance and training will be carried out. In addition to training and mentoring, this activity will plan to create an information system for villages based on raspberry pi, conduct entrepreneurship training for village officials and evening village communities to grow small industrial centers, for SME partners who are involved in addition to conducting training, an e-commerce system will be built. in order to increase the income of SMEs.
\end{abstract}

Keywords : Information System, Smart Village, Raspberry-pi 


\section{PENDAHULUAN}

Pendahuluan memuat tentang Desa Petang terletak di Kecamatan Petang, Kabupaten Badung. Desa ini berada di ketinggian 800 meter dari atas permukaan laut. Kurang lebih 32 kilometer sebelah utara kota Denpasar dan kira-kira 70 menit perjalanan bila menggunakan kendaraan bermotor dari Bandara Ngurah Rai Bali.

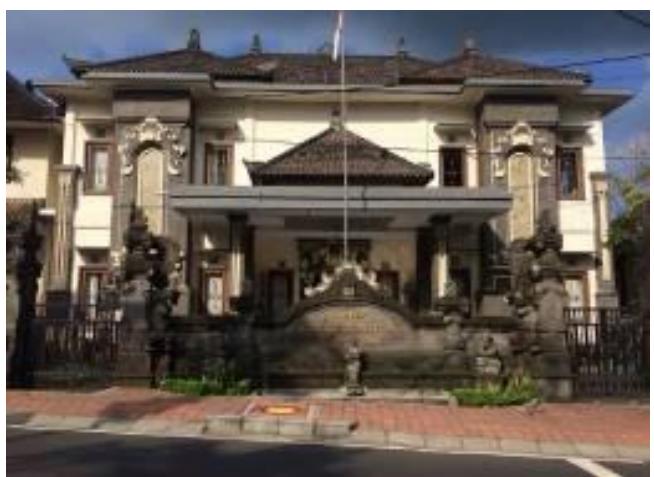

Gambar 1. Kantor Desa Petang

Desa Petang merupakan sebuah desa yang terletak di Kabupaten Badung, Provinsi Bali. Desa ini terdiri dari tujuh buah banjar dinas. Adapun kebudayaan yang beragam yang dimiliki oleh ketujuh banjar dinas ini. Dimulai dari keragaman kulinernya, seni musik tradisional, tempat wisata, tempat wisata rohani dan lain-lain. Desa petang dengan jumlah penduduk sebanyak 3984 Jiwa dengan jumlah penduduk laki laki 2034 Jiwa dan penduduk perempuan sebanyak 1950 jiwa, dengan jumlah kepala keluarga sebnyak $1050 \mathrm{KK}$. Dengan sebaran mata pencaharian berdasarkan data Monografi Desa Petang tahun 2015 sebagi berikut:

Tabel 1. Mata Pencaharian penduduk Desa Petang

\begin{tabular}{clc}
\hline No & Mata Pencaharian & Jumlah \\
\hline 1 & Karyawan: & \\
& PNS & 112 orang \\
& TNI/POLRI & 20 orang \\
& Karyawan & 480 orang \\
2 & Wirausaha & 406 orang \\
3 & Tani & 1810 orang \\
4 & Pertukangan & 274 orang \\
5 & Buruh Tani & 896 orang \\
6 & Pensiunan & 20 orang \\
\hline
\end{tabular}

Berdasarkan data nomografi desa petang diatas, terlihat bahwa kebanyakan penduduk berprofesi di bidang pertanian dan perdagangan termasuk kerajinan tangan. Oleh karena itu perlu pengembangan dan pelatihan dalam bidang pertanian dan perdagangan untuk lebih memajukan desa petang.

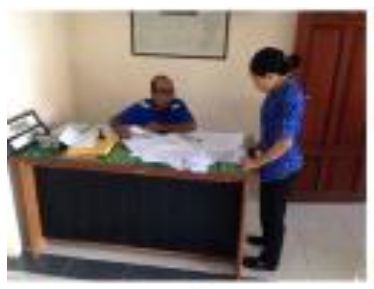

(a)

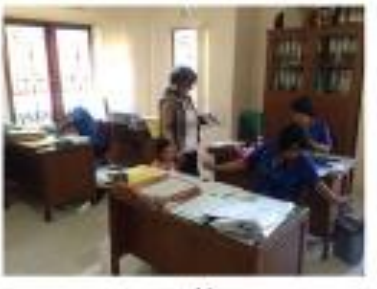

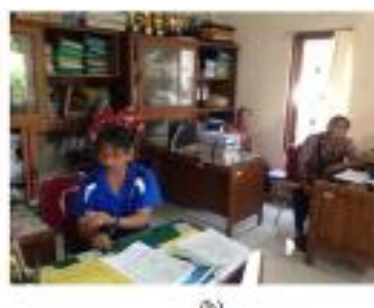

(6)
Gambar 2. Kegiatan Administrasi Desa Petang:

(a) Kepala Desa Petang

(b) Aparat Desa Petang

(c) Aparat desa sedang melayani masyarakat

Berdasarkan Profil Desa Petang, rata rata mata pencaharian penduduk adalah sebagai Petani, Pengrajin dan Wiraswasta. Wilayah Desa Petang terdiri dari 7 (tujuh) Banjar Dinas yang masing-masing memiliki seorang Kelian Banjar Dinas sebagai Staf Operasional Kepala Desa / Perbekel diwilayah kerjanya. Berikut Banjar Dinas tersebut adalah:

1. Banjar Dinas Petang Dalem Petangan

2. Banjar Dinas Petang

3. Banjar Dinas Petang Suci

4. Banjar Dinas Kerta

5. Banjar Dinas Lipah

6. Banjar Dinas Munduk Damping

7. Banjar Dinas Angantiga

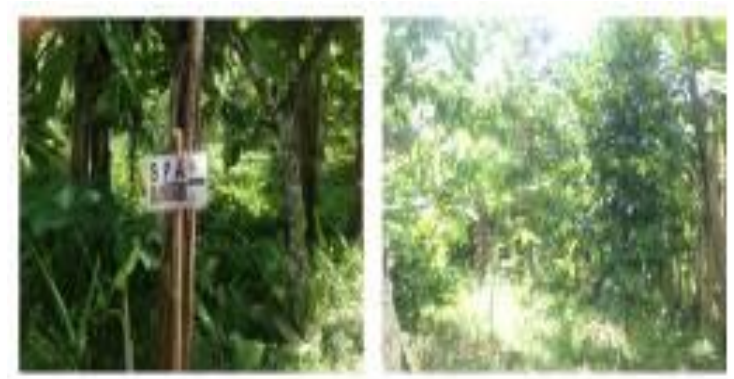

Gambar 3 Kebun Manggis Kelompok Petani Manggis Desa Petang 


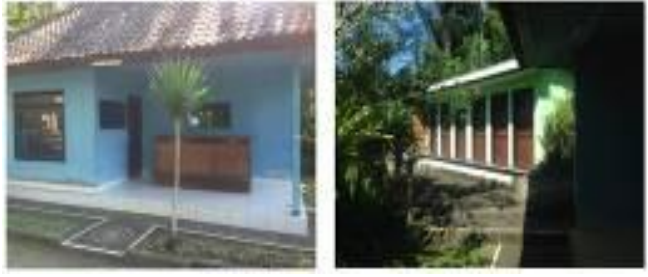

Gambar 4. Lokasi Surya Dewata Arung Jeram(Rafting)

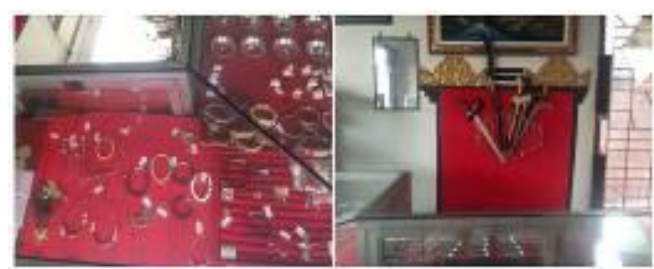

Gambar 5. Beberapa hasil kerajinan UKM Pengrajin Perak Desa Petang

Desa Petang memiliki potensi yang bisa dikembangkan mulai dari:

1. Berdasarkan Data Monografi desa petang, luas sawah adalah 61,50 Hektar dan luas kebun adalah 997,17 Hektar, hal ini terlihat bahwa perkebunan merupakan komoditas utama Agronomi dari Desa petang, Agronomi/Pertanian yang akan dikembangkan menjadi Agrowisata di Desa Petang manggis sebagai produk unggulannya. Desa Petang telah mengadakan festival Manggis pada bulan Mei dan dibuka langsung oleh Bapak Bupati Badung. Dalam hal ini Kabupaten Badung ingin menjadikan Desa Petang sebagai sentra penghasil manggis dengan kualitas yang bagus serta menjadikan Petang lokasi Agrowisata Manggis. Berita mengenai keinginan Bupati untuk menjadikan Desa Petang sebagai lokasi agrowisata dimuat

http://balitribune.co.id/content/festivalmanggis-di-petang, dan http://travel.kompas.com/read/2016/04/ 17/140000127/Mei.Ini.Liburan.AntiMainstream.di.Bali.Wisata.Manggis.di.D esa.Petang, serta di beberapa media lainnya.

2. Wisata Desa Petang sangat menjanjikan dikarenakan alamnya yang masih asri dan persawahan yangbertingkat serta terdapat sungai yang biasa dipergunakan untuk arung jeram dengan arus yang menantang dan pemandangan alam yang indah, tetapi masih belum terkenal karena kurangnya promosi dan pemasaran kegiatan arung jeram/rafting di Desa Petang.

3. Sentra kerajinan perak yang nantinya dapat dikembangkan menjadi tempat pusat belanja oleh oleh perak dengan kualitas yang bagus sehingga menjadikan UKM perak usaha berskala besar dengan pangsa pasar nasional dan internasaional

4. Potensi masyarakat yang masih perlu dikembangkan terutama dalam bidang wirausaha yang nantinya diharapkan akan menjadi sentra ekonomi masyarakat desa.

Dengan diadakannya pengabdian masyarakat ini diharapkan dapat membantu mengatasi permasalahan yang ada pada Desa Petang. Pada pengabdian masyarakat ini, kampus ITB STIKOM Bali menurunkan tim terbaiknya dalam mengatasi permasalahan yang ada pada masyarakat desa mulai dari Aparatur Desa, UKM, dan Masyarakat Desa Petang.

\section{METODE}

Prosedur kerja dari kegiatan ini ditunjukkan oleh gambar 6 . Terdapat enam bentuk kerja utama yang dimulai dari sosialisasi kegiatan, kemudian peningkatan kualitas dan jumlah produksi, kemasan yang lebih baik, peningkatan teknologi pemasaran, manajemen keuangan, serta evaluasi kegiatan.

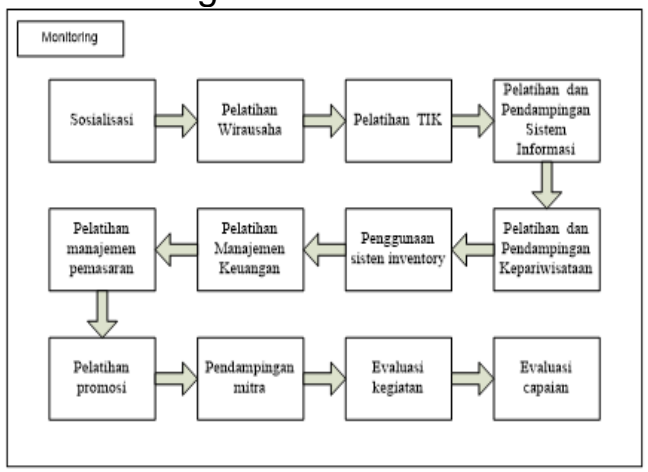

Gambar 6. Proses kerja kegiatan Ipteks

1 Melakukan pelatihan wirausaha yang dilakukan di desa petang dengan mengumpulkan masyarakat dan UKM mitra serta apataur Desa Petang. 
Pelatihan ini bertujuan menumbuhkan sentra sentra industi kecil pada masyarakat sehingga perkonomian menjadi lebih baik..

2 Menerapkan penggunaan TIK untuk aparatur desa guna meningkatkan kemampuan dalam pengelolaan desa. Dengan menggunakan TIK maka produktivitas dari aparatur desa akan meningkat

3 Menerapkan sistem informasi guna mengetahui potensi desa guna meningkatkan pembangunan. Sistem informasi disini adalah sistem informasi kependudukan yang nantinya akan dipergunakan oleh aparat desa dalam mengembangkan potensi desa

4 Menerapkan sistem informasi kepariwisataan bagi Desa Petang. Selama ini desa petang masih belum memiliki sistem informasi kepariwisataan, sehingga jumlah dari wisatawan yang datang ke desa petang masih kurang.

5 Menerapkan mengenai sisten inventry guna meningkatkan produktivitas UKM. Inventory merupakan inventaris, jadi dengan menerapkan sistem ini diharapakan UKM dapat mengetahui inventaris yang mereka miliki guna meningkatkan pengembangan selanjutnya.

6 Menerapkan majaemen keuangan bagi mitra UKM yang terlibat.

7 Menerapkan TIK untuk pemasaran bagu UKM mitra.

8 Mampu menggunakan media online untuk promosi

\section{HASIL DAN PEMBAHASAN}

Pada gambar 7 digambarkan proses identifikasi RFID yang ada dalam sistem.

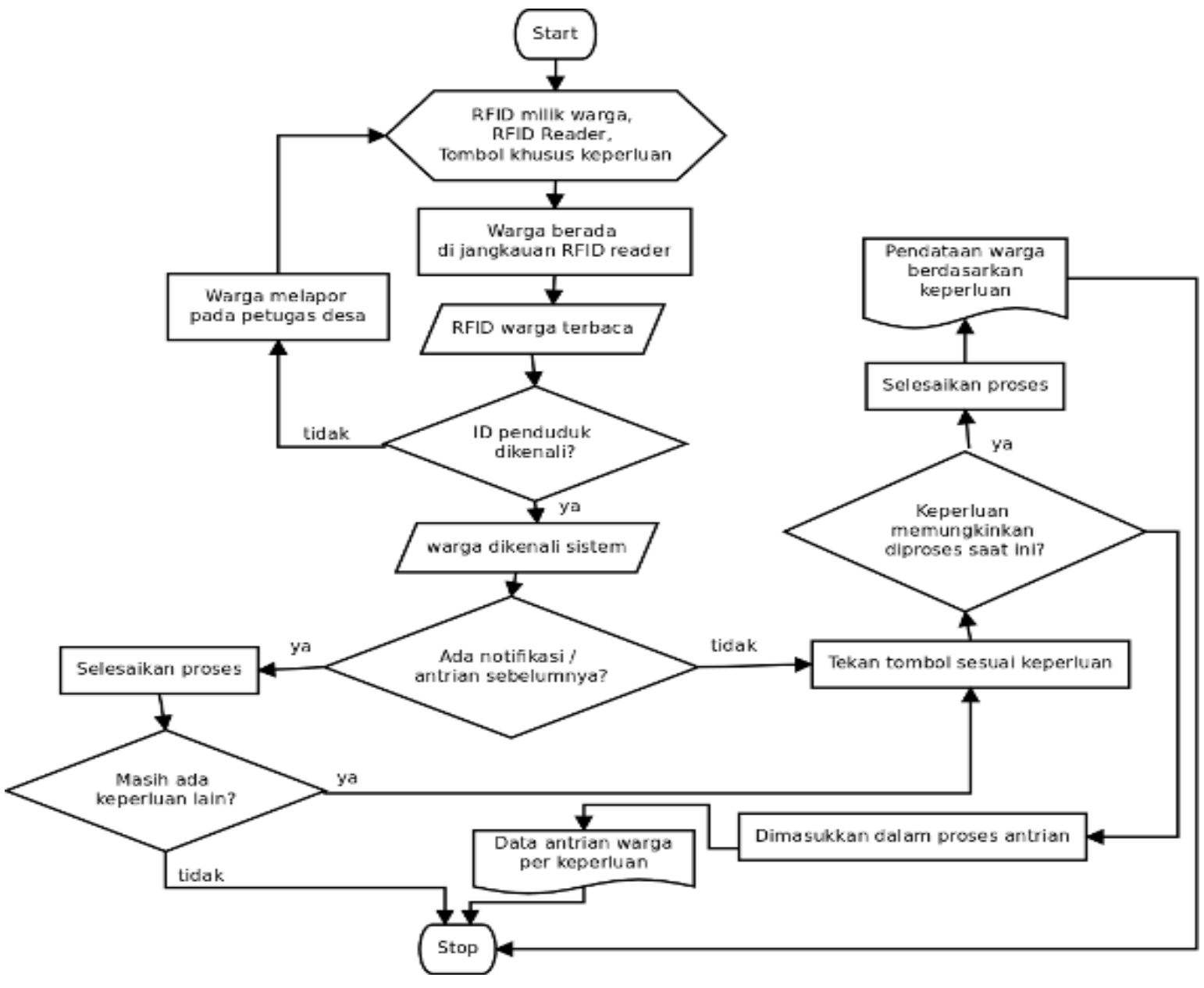

Gambar 7. Flow Chart proses Sistem secara Umum 
Proses dimulai dengan preparasi kartu RFID milik penduduk dan perangkar raspberry pi yang terdiri dari RFID Reader dan tombol untuk keperluan. Untuk teridentifikasi warga harus berada pada jangkauan RFID Reader. Jika tidak terbaca maka warga perlu menghubungi petugas kependudukan.

Setelah warga dikenali sistem, maka warga mendapatkan notifikasi tentang proses sebelumnya yang belum selesai atau dapat menekan tombol sesuai keperluan dokumen kependudukan mereka. Jika keperluan warga bisa di proses saat itu maka dokumen warga segera diproses, jika tidak maka permintaan warga dimasukkan dalam antrian..

Pada kegitan implementasi teknologi tepat guna telah dilaksanakan dan diimplemtasikan pada sistem desa petang. Juga telah dilakukan pelatihan dan pemdampingan pada aparatur desa dalam penggunaan sistem informasi berbasis raspberry-pi untuk desa petang.

Setelah sistem diimplemtasikan juga telah dilakukan followup berupa evaluasi penggunaan sistem kepada kepala desa dan perangkat desa tentang penggunaan sistem tersebut. pendataan penduduk dan unit kegiatan masyarakat (UKM) untuk perencanaan pengembangan desa. Tulisan ini dibuat sebagai penelitian pra penerapan dan evaluasi pada lokasi penerapan yaitu desa Petang.

Pada kegiatan implementasi ini dapat dilihat bahwa kegiatan yang dilaksanakan sudah berjalan dengan baik, sistem yang diimplementasikan sudah bisa dijalankan oleh aparat desa petang. Sebagaimana terlihat pada Gambar 9.

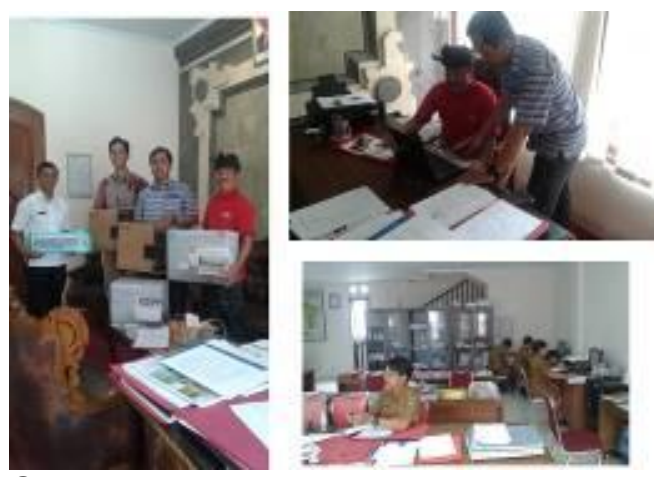

Gambar 8. Penyerahan Alat

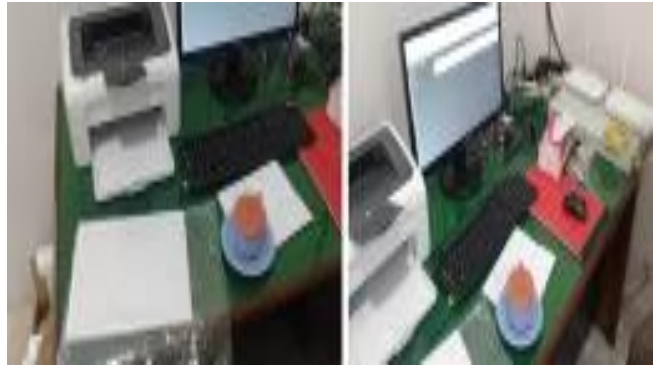

Gambar 9. Implemntasi Teknologi Tepat Guna

\section{KESIMPULAN}

Data penduduk pada sistem diinputkan oleh admin beserta data banjar dan UKM yang mereka ikuti. Penduduk dapat mengakses sistem melalui web atau membawa kartu RFID mereka ke kantor desa. Setelah penduduk teridentifikasi oleh sistem maka mereka bisa meminta proses dokumen yang mereka perlukan melalui menu web maupun tombol pada raspberry pi. Permintaan bisa langsung diproses atau masuk dalam antrian. Permintaan yang masuk dalam antrian akan memanggil penduduk lewat notifikasi web maupun pemanggilan manual jika penduduk berada di kawasan kantor desa. Implementasi teknologi Tepat Guna sudah dapat berjalan dengan baik dan sangat membantu kegiatan administrasi pada desa petang.

\section{DAFTAR PUSTAKA}

Ahmadi, C., \& Wedashwara, I. G. P. W. (2017). Implementasi Sistem Informasi Berbasiskan Open Cart 2.0. 0 . E-Proceedings KNS\&I STIKOM Bali, 815-819.

Cagnetti, M., Leccese, F., \& Trinca, D. (2013). A New Remote and Automated Control System for the Vineyard Hail Protection Based on ZigBee Sensors, Raspberry-Pi Electronic Card and WiMAX. Journal of Agricultural Science and Technology. B, 3(12B), 853.

Chatfield, A. T., Wamba, S. F., \& Tatano, H. (2010, January). E-government challenge in disaster evacuation response: the role of RFID technology in building safe and secure local communities. In System Sciences (HICSS), 2010 43rd Hawaii International Conference on 
(pp. 1-10). IEEE.

Dwipayana, M. P., Suastika, K., Saraswati, I. M. R., Gotera, W., Budhiarta, A. A. G., Gunadi, I. G. N., ... \& Kajiwara, N. (2011). Prevalensi sindroma metabolik pada populasi penduduk Bali, Indonesia. journal of internal medicine, 12(1).

Fry, E., \& Lenert, L. A. (2005, January). MASCAL: RFID Tracking of Patients, Staff and Equipment to Enhance HospitalResponse to Mass Casualty Events. In AMIA.

Hasibuan, Zainal A. "Langkah-langkah Strategis dan Taktis Pengembangan E-Government Untuk pemda." Jurnal Sistem Informasi MTI UI 3.1 (2007).

Maksimović, M., Vujović, V., Davidović, N.,
Milošević, V., \& Perišić, B. (2014).

Raspberry $\mathrm{Pi}$ as Internet of things hardware: performances and constraints. design issues, 3,8 .

Nomor, Undang-Undang. "tahun 2006 tentang Administrasi Kependudukan." Lembaran Negara Nomor 23 (23).

Rakitin, S. R. (2001). Software verification and validation for practitioners and managers. Artech House, Inc.

Wedashwara, W., Mabu, S., \& Ahmadi, C. (2017, August). Parallel evolutionary association rule mining for efficient summarization of wireless sensor network data pattern. In 2017 5th International Conference on Cyber and IT Service Management (CITSM) (pp. 1-6). IEEE. 